\title{
Critical illness polyneuropathy and myopathy: a review
}

Maria-Luisa Hohl RN; Crit Care Cert, ICU Nurse, Ospedale Regionale Bellinzona e Valli, 6500 Bellinzona, Switzerland.

Key words: critical illness polyneuropathy myopathy risk factors long-term outcome

E-mail: mlhohl@bluewin.ch

\section{SUMMARY}

- The pathophysiology of critical illness polyneuropathy and myopathy (CIPNM) is not fully understood.

- $\quad$ Risk factors of CIPNM are systemic inflammatory response syndrome (SIRS), multiple organ failure and, possibly, high blood glucose levels.

- $\quad$ The risk of developing CIPNM for ventilated patients can be assessed based on the presence of SIRS and APACHE III scoring.

- Early electrophysiological testing can detect CIPNM, although no specific treatment is currently available.

- $\quad$ To date nursing and nursing and physiotherapy interventions have been poorly investigated.

- Chronic disability affects some survivors, and functional impairment and weakness can last up to four years.

\section{INTRODUCTION}

After a severe illness requiring a prolonged period of mechanical ventilation and sedation, intensive care patients very often present with generalised neuromuscular weakness (Garnacho-Montero et al., 2001; Khilnani \& Bansal, 2004). During the critical phase of a major illness, such as severe sepsis, pneumonia, adult respiratory distress syndrome (ARDS) or major surgery, the aims of treatment include addressing the primary disease and avoiding known complications such as multiple organ failure (MOF).

The neuromuscular complication that often affects patients after critical illness results from polyneuropathy or myopathy. Critical illness polyneuropathy (CIP) is axonal peripheral degeneration of motor and sensory nerves, whereas critical illness myopathy (CIM) is a motor nerve only deficit, in which muscle atrophy is common. CIP often coexists with CIM (Coakley et al., 1998; Khilnani \& Bansal, 2004) and it is not always possible to differentiate between the two. There is no universal agreement on how to label these disorders, which are characterised by clinical or electrophysiological evidence of neuromuscular weakness with no primary neurological disorder. Thus, for the purpose of this review the allencompassing term critical illness polyneuropathy and myopathy (CIPNM) has been used.

When patients survive, and the critical phase of illness is over, they often experience problems with functional recovery due to the effects of CIPNM, which develop commonly (de Letter et al. 2001; Fletcher et al., 2003; Bercker et al., 2005). In these situations nurses must care sensitively for patients who frequently become difficult to wean from the ventilator, and who may not be able to provide perform normal daily activities such as communicating effectively, changing their body position, and eating and drinking. Thus, patients who are recovering from a life-threatening illness often have to face a condition of high dependency. Their recovery phase may be long-lasting and can be a source of frustration for patients, carers, nurses, physicians and physiotherapists.

In the literature, although recovery from CIPNM is reported to be good (Fletcher et al., 2003; Khilnani \& Bansal, 2004; Van den Berghe et al., 2005), this is in contrast to my own observations. For example, some patients who I have cared for are still using a wheelchair a year or more after their illness. For this reason, and to understand better how nurses can support patients with CIPNM, I undertook a review of the literature to address the following questions:

- What is the pathophysiology of CIPNM?

- $\quad$ Are there tools available to assess the risk of a patient developing CIPNM?

- $\quad$ Is it possible to diagnose CIPNM early and to treat it before it appears clinically?

- What treatments are useful for CIPNM; especially nursing and physiotherapy interventions?

- How long and to what extent are patients disabled after CIPNM?

For the purpose of this review the following definitions were used:

- $\quad$ Critical illness polyneuropathy (CIP): axonal peripheral degeneration of motor and sensory nerves,

- $\quad$ Critical illness myopathy (CIM): a motor nerve (only) deficit in which muscle atrophy is common.

\section{SEARCH STRATEGY}

An initial search was undertaken, using the MEDLINE database (1998 to date) to search for full text articles. The following search terms were used: polyneuropathy and critical illness not GuillainBarré and /prevention, /rehabilitation, /risk assessment, /nursing. A subsequent search of the Cochrane Collaboration and CINHAL databases was undertaken, but resulted in no further articles. An article was selected by examining its title and abstract for relevance, and its on-line availability through the university library. To facilitate selection of the articles for the review a literature map was produced (see Figure 1). Using this map helped to maintain the focus of the review on the risk factors (where treatment can be implemented to prevent CIPNM), and on the long term outcome (to understand better how CIPNM affects the recovery of the patients after hospital discharge). 


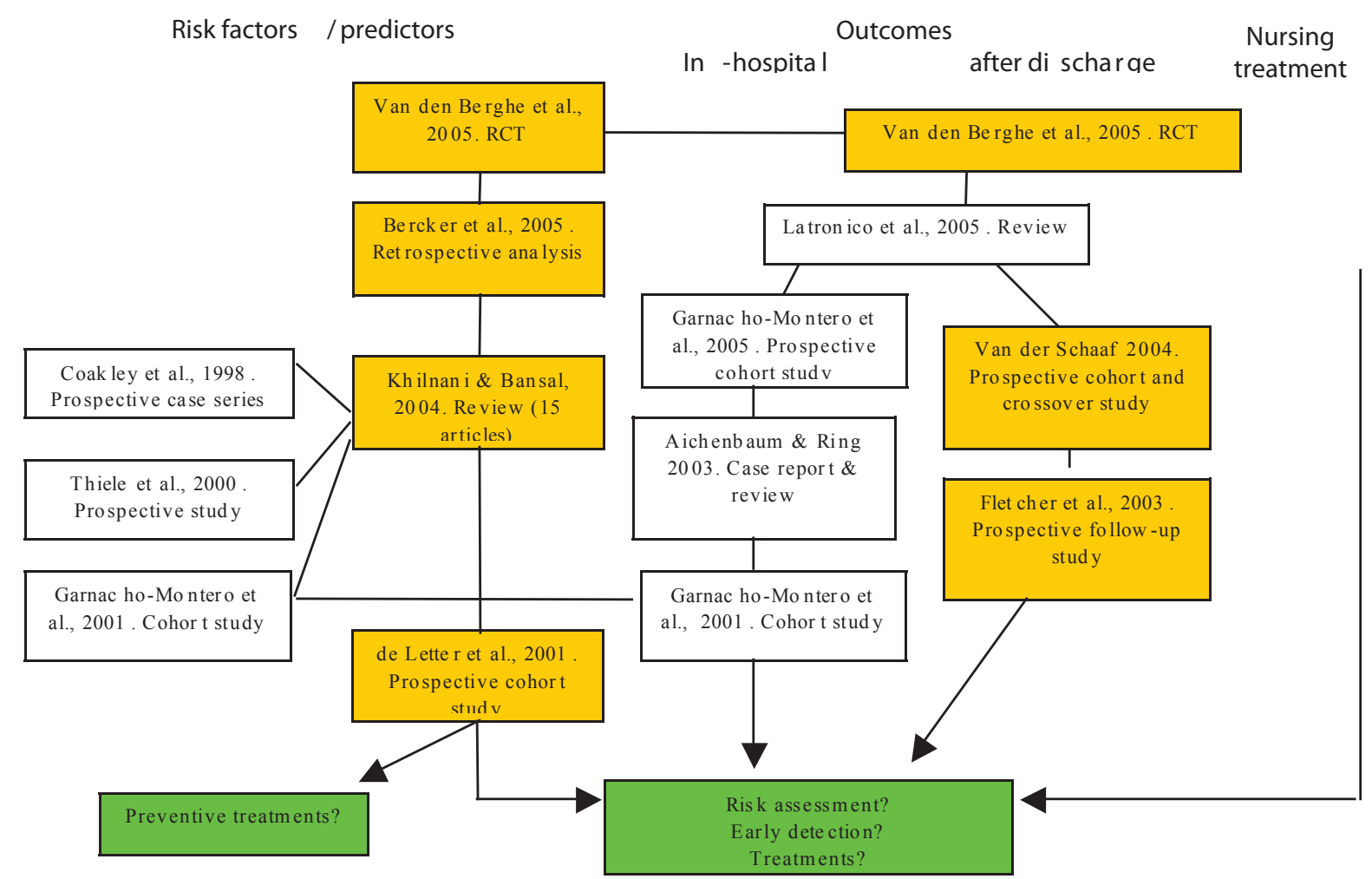

Figure 1. Literature map showing the retrieved articles. The yellow boxes indicate the articles that were selected for the review.

Thirteen articles were retrieved initially. Of these, eight reported studies that dealt with prevention issues and four examined rehabilitation. No studies were identified that dealt with risk assessment. Three of the articles on risk factors were included in the review by Khilnani and Bansal (2004), so this article was selected for review, in addition to three later studies (de Letter et al., 2001; Bercker et al., 2005; Van den Berghe et al., 2005). Two further articles addressed long-term outcomes (Fletcher et al., 2003; Van der Schaaf, Beelen, \& De Vos, 2004). Table 1 provides an overview of the six articles, which are summarised in the following section.

\section{LITERATURE SUMMARY}

Bercker et al. (2005) performed a retrospective analysis of 50 ARDS patients, who were transferred to an academic intensive care unit (ICU) in Germany. The purpose of the study was to determine the risk factors for CIPNM and the validity of electrophysiological testing as an early diagnostic tool to predict paresis. A wide range of predictors was gathered using charts. Patients with elevated blood glucose levels during their ICU admission showed a higher incidence of CIPNM and were also older, with age and hyperglycaemia correlating significantly. A high percentage $(60 \%)$ of patients had CIPNM, longer ICU length of stay (LOS) and longer mechanical ventilation. In ARDS patients, electrophysiological testing predicted paresis reliably and could be useful to identify those patients that need longer respiratory support and who should not undergo early weaning trials.

An earlier prospective single centre study by de Letter et al. (2001) aimed to identify the risk factors of development of CIPNM with a very precise and rigorous design. Critically ill patients were monitored with respect to the conditions thought to play a role in previous and sometimes contradictory studies. The authors found that only the Acute Physiology and Chronic Health Evaluation (APACHE) III score and the presence of systemic inflammatory response syndrome (SIRS) were significant predictors for the development of CIPNM. Based on this finding they were able to determine three risk groups. The overall incidence of CIPNM in this sample of 98 patients was $33 \%$. Within 30 days of artificial ventilation the probability of developing CIPNM ranged from $8 \%$ for the low-risk group to $72 \%$ for the high-risk group.

In a five-year prospective follow-up study, Fletcher et al. (2003) studied long-term neuromuscular dysfunction in ICU patients after prolonged critical illness with the intent to determine its prevalence, clinical characteristics, and electrophysiological features. Of 195 patients from three UK hospitals with an ICU stay longer than four weeks, 22 were assessed using a full neurological examination and a series of neurophysiological tests. Further data were collected using hospital charts and a clinical history was also taken. The group of recruited patients was similar to the whole survivor group comparing median age, APACHE II score, ICU stay and hospital stay. The follow-up examination occurred after a median time of 43 months from ICU discharge and showed motor or sensory deficits in 59\% of the patients, though only a few had a serious disability. All patients reported that they had functional impairment at discharge from the hospital and had a prolonged recovery period and severe weakness. Neurophysiological testing showed CIP in $90 \%$ of the long-stay ICU patients, up to five years after discharge.

The review by Khilnani and Bansal (2004) is very informative 


\begin{tabular}{|c|c|c|c|c|c|c|}
\hline & $\begin{array}{l}\text { De Letter et al., } \\
2001\end{array}$ & $\begin{array}{l}\text { Fletcher et al., } \\
2003\end{array}$ & $\begin{array}{l}\text { Khilnani \& } \\
\text { Bansal, 2004 }\end{array}$ & $\begin{array}{l}\text { Van der Schaaf } \\
\text { et al., } 2004\end{array}$ & \begin{tabular}{|l} 
Bercker et al., \\
2005
\end{tabular} & $\begin{array}{l}\text { Van den Berghe } \\
\text { et al., } 2005\end{array}$ \\
\hline Aim/design & $\begin{array}{l}\text { - Identify the risk } \\
\text { factors in the devel- } \\
\text { opment of CIPNM } \\
\text { - Single centre lon- } \\
\text { gitudinal prospec- } \\
\text { tive observational } \\
\text { study (5'94-7 } \\
\text { '96) }\end{array}$ & $\begin{array}{l}\text { - Establish the } \\
\text { prevalence, electro- } \\
\text { physiological fea- } \\
\text { tures and residual } \\
\text { neuromuscular dys- } \\
\text { function } \\
\text { - Prospective fol- } \\
\text { low-up (1.'93- } \\
12 . ' 97)\end{array}$ & $\begin{array}{l}\text { - Review } \\
\text {-4 case reports, } \\
\text { other designs not } \\
\text { stated }\end{array}$ & $\begin{array}{l}\text { • Evaluate func- } \\
\text { tional outcome in } \\
\text { CIP patients. } \\
\text { - Single centre pro- } \\
\text { spective cohort (03- } \\
05 / 1999)+ \text { cross } \\
\text { sectional study } \\
\text { (09/1998-02/1999). }\end{array}$ & $\begin{array}{l}\text { - Evaluate inci- } \\
\text { dence, risk factors, } \\
\text { complications of } \\
\text { CIP paresis. } \\
\text { - Assess reliability } \\
\text { of early electro- } \\
\text { physiological test- } \\
\text { ing. } \\
\text { - Single centre, } \\
\text { retrospective } \\
\text { analysis }(05 / 1998 \\
-11 / 2001)\end{array}$ & $\begin{array}{l}\text { - Effects of intensive } \\
\text { insulin therapy on } \\
\text { outcome of critical } \\
\text { illness } \\
\text { - Single centre RCT } \\
\text { - Intervention: strict } \\
\text { glycaemic control } \\
\text { (<6.1 mmol/L) }\end{array}$ \\
\hline Sample & $\begin{array}{l}\text {-98 critically ill } \\
\text { pat. (from day } 4 \text { of } \\
\text { artificial respiration) } \\
\text { - Multiple trauma, } \\
\text { surgery, infectious } \\
\text { disease and others }\end{array}$ & $\begin{array}{l}\text { - From } 195 \text { patients } \\
\text { with ICU length } \\
\text { of stay }>28 d, 86 \\
\text { survivors identified, } \\
47 \text { eligible, } 22 \text { con- } \\
\text { sented }\end{array}$ & $\begin{array}{l}\text { - Review strategy } \\
\text { not stated } \\
\text { - Table of } 15 \\
\text { articles } \\
\text { - Different patient } \\
\text { groups }\end{array}$ & $\begin{array}{l}\text { • Eligible: sepsis or } \\
\text { MOF, mechanically } \\
\text { ventilated }>7 \text { days, } \\
\text { no previous ortho- } \\
\text { paedic or neuro- } \\
\text { logical disorders. } \\
\text { •Cohort: from } \\
61,22 \text { eligible, } 8 \\
\text { included with CIP. } \\
\text { • Cross sectional: } 8 \\
\text { patients included } \\
\text { (CIP in the past } 6 \\
\text { months). }\end{array}$ & $\begin{array}{l}\text { - } 50 \text { adult ARDS } \\
\text { patients: } 27 \\
\text { CIPNM; } 18 \text { control; } \\
5 \text { deaths }\end{array}$ & $\begin{array}{l}\bullet \text { RCT: } \mathrm{n}=1548 \\
\bullet \text { Adult ICU long- } \\
\text { stay pat. ( } \geq 7 \mathrm{~d} \text { ) } \\
\text {-Pre-planned sub- } \\
\text { analysis: subgroup } \\
\text { screened for CIP: } \\
\mathrm{n}=405 \text {; subgroup } \\
\text { isolated brain } \\
\text { injury: } \mathrm{n}=63\end{array}$ \\
\hline Diagnosis & $\begin{array}{l}\text {-CIPNM = clinical } \\
\text { + electrophy-sio- } \\
\text { logical criteria }\end{array}$ & $\begin{array}{l}\text { - Neurophysiologic } \\
\text { studies: weakness }= \\
\text { MRC scale } \leq 4 \\
\bullet \text { Only } 2 \text { patients } \\
\text { with CIP diagnosed } \\
\text { during ICU stay }\end{array}$ & -Not described & $\begin{array}{l}\text { - Limb muscle } \\
\text { strength grade MRC } \\
\leq 4 \text { at awakening, } \\
\text { diagnosis con- } \\
\text { firmed by electro- } \\
\text { myo-graghy }\end{array}$ & $\begin{array}{l}\bullet \text { CIPNM = clinical- } \\
\text { ly relevant paresis } \\
\text { after recovery from } \\
\text { sedation }\end{array}$ & $\begin{array}{l}\text {-CIP: electromyog- } \\
\text { raphy } \\
\text { - Rehabilitation: } \\
\text { KPS at discharge, } 6 \\
\text { and } 12 \text { months post } \\
\text { discharge }\end{array}$ \\
\hline
\end{tabular}




\begin{tabular}{|c|c|c|c|c|c|c|}
\hline $\begin{array}{l}\text { Diagnostic tool } \\
\text { risk assessment }\end{array}$ & $\begin{array}{l}\bullet \text { Three risk groups } \\
\text { were determined: } \\
\text { Low-risk ( } 8 \% \text {; } \\
\text { APACHE III } \leq 70+ \\
\text { no SIRS); High risk } \\
\text { ( } 72 \% \text {; APACHE III > } \\
85+\text { SIRS); Medium } \\
\text { risk (28\%; all other } \\
\text { patients }\end{array}$ & & \begin{tabular}{|l|}
-Diagnosis: high \\
index of suspicion \\
and detailed neu- \\
rological examina- \\
tion supported by \\
electrophysiological \\
tests \\
- Pre-existing poten- \\
tial risk factors: \\
neuromuscular dis- \\
ease, diabetes mel- \\
litus, alcoholism, \\
HIV, malignancy \\
and renal failure
\end{tabular} & $\begin{array}{l}\bullet 1 \text { year mortality } \\
56 \% \\
\bullet \text { At } 6 \text { months ( } 4+4 \\
\text { patients): all good } \\
\text { muscle strength } \\
\text { (MRC } \geq 3 \text { ), sensory } \\
\text { function impaired } \\
\text { for } 6 \text {; problems in } \\
\text { ADL function for } \\
\text { many; all but } 1 \\
\text { outdoor mobility } \\
\text { restricted; quality } \\
\text { of life moderate to } \\
\text { bad, } 7 \text { patients on } \\
\text { physiotherapy treat- } \\
\text { ment. } \\
\text { • At } 12 \text { month (2 + } \\
3 \text { patients): physical } \\
\text { health improved } \\
\text { for all; functional } \\
\text { impairment domi- } \\
\text { nant in } 4 \text {; outdoor } \\
\text { mobility reduced } \\
\text { with impact on } \\
\text { autonomy and par- } \\
\text { ticipation in social } \\
\text { relations; quality of } \\
\text { life unsatisfactory } \\
\text { for all but } 1 \text {. }\end{array}$ & $\begin{array}{l}\bullet \text { Mean blood glu- } \\
\text { cose levels }>170 \\
\mathrm{mg} / \mathrm{dL}(9.4 \mathrm{mmol} / \mathrm{L}) \\
\text { positive predictive } \\
\text { value to develop } \\
\text { paresis }(92 \%) \\
\text { - Electrophysiologic } \\
\text { testing = reliable } \\
\text { diagnostic tool to } \\
\text { predict paresis }\end{array}$ & \\
\hline Outcomes & & $\begin{array}{l}\text {-At hospital dis- } \\
\text { charge: severe } \\
\text { weakness and func- } \\
\text { tional impairment } \\
\text { in all patients } \\
\text {-At follow-up: } \\
\text { sensory deficit: } 6 \\
(27 \%) \text {, motor weak- } \\
\text { ness: } 4(18 \%) \text {, both: } \\
3(14 \%) \\
\text {-Clinically evident } \\
\text { weakness up to } \\
4 \text { years in some } \\
\text { patients } \\
\text { •Denervation signs } \\
\text { in } 90 \% \\
\text { - Few with serious } \\
\text { disability }\end{array}$ & $\begin{array}{l}\text { - After recovery: } \\
\text { high medical and } \\
\text { psychosocial costs. } \\
\text { - CIP increases } \\
\text { mortality and sec- } \\
\text { ondary morbidity } \\
\text { - Mortality } 48 \% \\
\text { (CIPNM) vs. } 19 \% \\
\text { - CIP responsible in } \\
17 \% \text { cases of dif- } \\
\text { ficult weaning } \\
\text { - Acute neuromus- } \\
\text { cular respiratory } \\
\text { failure after suc- } \\
\text { cessful weaning, } \\
\text { with ICU readmis- } \\
\text { sion or death } \\
\text { - Most conditions } \\
\text { are reversible and } \\
\text { carry good prog- } \\
\text { nosis }\end{array}$ & & $\begin{array}{l}\bullet \text { ICU length of stay } \\
38 \text { days (CIPNM) } \\
\text { vs. } 26(p=.001) \\
\bullet \text { Ventilator days } 20 \\
\text { (CIPNM) vs. } 13 \text { ( } p \\
=.018)\end{array}$ & $\begin{array}{l}\text {-Ventilator days, } \\
\text { median } 11 \text { vs. } 13 \text { ( } p \\
=0.02 \text { ) } \\
\text { • Prolonged ventila- } \\
\text { tion, }>14 \text { days, } 32 \% \\
\text { vs. } 42 \%(p=0.04) \\
\bullet \text { Mortality } 12 \% \text { vs. } \\
21 \%(p=0.01) \\
\bullet \text { Shorter ICU stay, } \\
\text { bacteraemia, time } \\
\text { on antibiotics } \\
\text { - At } 12 \text { months a } \\
\text { larger fraction of } \\
\text { survivors after iso- } \\
\text { lated brain injury in } \\
\text { the IT group reha- } \\
\text { bilitated to a level } \\
\text { of independent } \\
\text { living }\end{array}$ \\
\hline Comments & $\begin{array}{l}\text { - Limited gener- } \\
\text { alisability: single } \\
\text { centre } \\
\text { - Interesting: risk } \\
\text { groups }\end{array}$ & $\begin{array}{l}\text { - Limited generalis- } \\
\text { ability: multi centre } \\
\text { design, but high } \\
\text { level of drop-outs. } \\
\text { - Strength: system- } \\
\text { atic assessment of } \\
\text { CIPNM }\end{array}$ & $\begin{array}{l}\bullet \text { Informative } \\
\text { review, easy to } \\
\text { read. } \\
\text { - Reviewed stud- } \\
\text { ies not described: } \\
\text { level of evidence } \\
\text { unknown. }\end{array}$ & $\begin{array}{l}\text {-Well designed, } \\
\text { but small sample. } \\
\text { - Limited gener- } \\
\text { alisability: single } \\
\text { centre. } \\
\text { - Impairment at } 1 \\
\text { year confirmed by } \\
\text { different tools. }\end{array}$ & $\begin{array}{l}\text { - Limited gener- } \\
\text { alisability: single } \\
\text { centre }\end{array}$ & $\begin{array}{l}\text {-Well designed. } \\
\text { - Limited gener- } \\
\text { alisability: single } \\
\text { centre. } \\
\text { - Long-term findings } \\
\text { only on subgroup }\end{array}$ \\
\hline
\end{tabular}

Table 1. Overview of articles on CIPNM 
and illustrates the possible disorders that lead to neuromuscular weakness in critically ill patients, the postulated pathopysiological mechanisms for CIPNM and the related risk factors. Their review suggests that the incidence of the disease is high and that the diagnosis can be difficult because different disorders are involved, different underlying illnesses are likely to be present, and neurological examination is complex.

Van den Berghe et al. (2005) reported the findings of a subset analysis of a large randomised controlled trial of 1548 ICU patients. Their main study was designed to investigate the effect of intensive insulin therapy on the outcome of critical illness. 181 patients in the intervention group were given insulin therapy to maintain blood glucose levels below $6.1 \mathrm{mmol} / \mathrm{L}$, whereas the control group of 224 patients received conventional therapy in which blood glucose levels of $12 \mathrm{mmol} / \mathrm{L}$ or higher were treated. Patients in ICU for seven days or longer $(n=405)$ were assessed regularly for CIP. The primary outcome measures included CIP assessment with electromyography, number of ventilator days, and mortality. Patients were randomised after stratification by admission groups, permitting a sub-analysis of 63 patients with isolated brain injury in whom short and long term outcomes were measured. The ability of patients to meet most of their own care needs was measured as a long term outcome using the Karnofsky Performance Score (KPS), and was found to be significantly higher in the intervention group.

Van der Schaaf et al. (2004) measured functional outcome of CIP patients at six and twelve months after discharge. Various instruments and scales were used to assess body function including muscle strength using the Medical Research Council (MRC) scale, sensory function, physical functions such as activities of daily living (ADL), autonomy, family role, and social relations. Perceived quality of life was also assessed. All instruments had been previously validity and reliability tested. Two designs were used for this study: a prospective cohort study of eight consecutive patients with CIP and a cross-sectional study of eight patients with a diagnosis of CIP made in the six months prior to enrolment. The results showed a high mortality rate in this group of long-term (that is, greater than 7 days) ventilated patients with sepsis or MOF; only five could be followed up at one year. This group demonstrated persistent handicaps, and restricted autonomy and social participation. These results are in contrast to the widespread opinion that recovery of survivors with CIP is good.

\section{DISCUSSION}

\section{Neuromuscular weakness}

The pathopysiological mechanisms that lead to neuromuscular weakness are not clear. Probably microcirculation is disturbed by various mechanisms (increased endovascular resistance, increased permeability, and lack of autoregulation), which cause hypoxia and lead to axonal degeneration (Khilnani \& Bansal, 2004).

The incidence of CIPNM varies depending on the population under study. It can range from $33 \%$ in patients who are mechanically ventilated up to $70 \%$ in patients with sepsis and MOF (de Letter et al., 2001; Khilnani \& Bansal, 2004). Early diagnosis of CIPNM is possible with electrophysiological studies, which detect the disease within two to three weeks (de Letter et al., 2001), but there is still a clinical question as to the relevance of making an early diagnosis when there is no specific treatment available. However, Bercker et al. (2005) suggest that early weaning trials should be avoided in ARDS patients with CIP to avoid further muscular distress. In this respect, a reliable prediction of neuromuscular weakness could be important, and this is an area that needs further research. Moreover, a diagnosis of CIPNM might influence nurses' approach to weaning. Because neuromuscular weakness causes difficult weaning, delayed extubation, and acute respiratory failure with ICU readmission or death, different weaning procedures should be used (Khilnani \& Bansal, 2004; Garnacho-Montero et al., 2005). Furthermore, it is possible that early and intensive rehabilitation would shorten the whole rehabilitation process and reduce residual disability in patients surviving a critical illness with CIPNM, but this has been barely investigated (Aichenbaum \& Ring, 2003; Van der Schaaf et al., 2004). Therefore, with respect to the possible need for different nursing approaches to weaning and rehabilitation for patients with neuromuscular weakness, early diagnosis would be of significance.

In clinical practice, however, CIPNM often remains undetected (Garnacho-Montero et al., 2001). For example, Fletcher et al. (2003) found only two patients diagnosed with CIP during their ICU stay, although 21 patients had some degree of CIP when they were followed up. Clinical examination is essential for the diagnosis of neuromuscular weakness and should be performed systematically on every ICU patient awakening after long-term mechanical ventilation. Muscle strength is most often assessed using the MRC classification, which defines limb weakness as grade 4 or less (Fletcher et al., 2003; Van der Schaaf et al., 2004). In addition, the use of electrophysiological tests is supported by all authors in this review.

\section{Risk factors}

The presence of sepsis, SIRS and/or MOF is a major and well established risk factor for the development of CIPNM. For this reason aggressive therapy should be aimed at the reduction of systemic inflammation and the avoidance of organ failure. Based on the presence of SIRS, de Letter et al. (2001) determined risk groups for developing CIPNM; their categories can be used in clinical practice to assess the level of risk of patients:

- $\quad$ high risk (72\%): initial APACHE III score $\geq 85$ and SIRS,

- $\quad$ medium risk (28\%): APACHE III score 71-84

- Iow risk (8\%): APACHE III score $\leq 70$ and absence of SIRS.

When initial assessment indicates abnormal neurological function an electromyogram is recommended to diagnose CIPNM.

\section{Blood glucose levels}

In addition to their role in monitoring and helping to prevent and treat systemic inflammation and organ failure, nurses have an important task in the prevention of CIPNM by tightly controlling blood glucose levels. In the single centre randomised clinical trial by Van den Berghe et al. (2005) strict control of blood glucose level was maintained at under $6.1 \mathrm{mmol} / \mathrm{L}$, producing a significant reduction in the incidence of CIPNM (25\% versus $49 \%$, $\mathrm{p}<0.0001)$. The benefits of intensive insulin therapy were also shown to lower median ventilator days, to reduce the incidence of mechanical ventilation periods of longer than 14 days, and to reduce mortality $(12 \%$ versus $21 \%, \mathrm{p}=0.01)$.

Bercker et al.'s (2005) retrospective analysis of adults with ARDS permitted calculation of mean daily peak glycaemia. When the patient's blood glucose level peaked above $9.4 \mathrm{mmol} / \mathrm{L}$ it was a 
positive predictor of paresis. Although this test had good specificity $(94 \%)$ its low sensitivity (44\%) meant that lower glucose levels did not predict the absence of CIPNM.

\section{Drugs}

Early studies on CIP suggested that several drugs were related to its onset; most commonly corticosteroids, muscle relaxants, and aminoglycoside antibiotics (Garnacho-Montero et al., 2001; Bercker et al., 2005). However, the three studies on risk factors in this review did not confirm these findings. Although they were single centre studies, they used large sample sizes [sample sizes in these studies were larger than those in the studies reviewed by Khilnani and Bansal (2004)] and were conducted rigorously. In all three studies, no significant differences were found regarding particular drugs and the onset of CIPNM. Moreover, the use of these medications is strongly correlated with the primary critical illness and sepsis. For example, in de Letter et al.'s (2001) prospective study SIRS and the use of aminoglycosides were significantly related $(p=0.03)$.

\section{Long-term outcomes}

Research into the long-term outcome of CIPNM is difficult to undertake. This is in part due to the high in-hospital mortality of critically ill patients, with many deaths occurring soon after discharge. Other problems include the difficulties of enrolling participants and the absence of disease specific assessment tools.

In three studies (Fletcher et al., 2003; Van der Schaaf et al., 2004; Van den Berghe et al., 2005) disability, quality of life and independence were assessed. However, because different assessment tools were used the comparison of results is difficult. Although some improvement from neuromuscular weakness occurs in almost all patients after hospital discharge, recovery is often incomplete (Garnacho-Montero et al., 2005; Latronico et al., 2005). Patients with long ICU stays leave hospital with severe weaknesses and functional impairment (Fletcher et al., 2003) and their rehabilitation may last for a very long time. For example, in the study by Van der Schaaf et al. (2004) seven out of eight patients were still receiving physiotherapy treatment at six months following discharge. Long term serious disability is relatively infrequent but some functional impairment at one year - and up to four years - was found in two recent studies (Fletcher et al., 2003; Van der Schaaf et al., 2004).

\section{CONCLUSIONS}

No specific treatment for CIPNM is available and the management of neuromuscular weakness is primarily supportive (GarnachoMontero et al., 2001; Latronico et al., 2005). However, the findings of Van den Berghe et al. (2005) are important in that they show a beneficial impact on recovery. Their evidence is quite persuasive and suggests that the maintenance of blood glucose level under 6.1-6.5 mmol/L is a factor in the prevention of CIPNM, and nurses have an important role to play in controlling glycaemia with intensive insulin therapy. Nevertheless, it would be inadvisable to generalise the results of this study of a small group of patients with brain injury to the wider population of critically ill patients. Further research will help to provide additional evidence of the clinical relevance to CIPNM of tight blood glucose control.

The literature search did not reveal any articles that described nursing interventions for CIPNM patients. It could be speculated that sensory deprivation, which occurs during critical illness due to immobilisation and sedation, may play a role in the onset of neuromuscular weakness and that nursing interventions, such as basal stimulation, might be effective in reducing sensory impairment. Nursing research might address the role of sensory stimulation of critically ill patients to improve the outcome. Multi-centre studies are required to assess (potentially) preventative measures and treatments that could reduce the incidence of CIPNM or improve outcomes such as the duration of mechanical ventilation, intensive care LOS and readmission, functional impairment, and mortality rates. Surprisingly, no studies in the review addressed the effectiveness of early and intensive physiotherapy to improve the rehabilitation process. This is an area that merits further research.

Since survival of critical illness is improving due to better treatment of sepsis and prevention of organ failure (Fletcher et al. 2003; Van der Schaaf et al., 2004), it is likely that the incidence of CIPNM will increase in the future. Persistent functional impairment is likely to affect patients' autonomy, social functioning and their quality of life and may be associated with high medical and psychosocial costs. Hence, research following hospital discharge is needed to describe long-term outcome in more detail and to identify rehabilitation problems in order to provide optimal treatment. This might require the development of new disease-specific assessment tools.

\section{RECOMMENDATIONS FOR CLINICAL PRACTICE AND FURTHER RESEARCH}

Gaining knowledge on the pathopysiological mechanisms that lead to neuromuscular weakness may lead to specific treatments in the future. In clinical practice, the diagnosis of CIPNM could be improved by systematically assessing every ICU patient following long-term mechanical ventilation and the maintenance of tight control of blood glucose level seems to be promising to reduce the incidence CIPNM, long-term disability, and mortality. However, to date the evidence base is relatively weak, and a higher level of evidence is needed before firm recommendations can be made for practice.

The appropriateness of specific weaning and rehabilitation protocols for the patient with CIPNM requires further study. Clinical research should address the role of passive mobilisation, sensory stimulation and early and intensive rehabilitation to promote independent living after a long ICU stay.

Large scale studies with rigorous methodology are required to gather further evidence of the existence of CIPNM and its impact on the individual and on society.

\section{LIMITATIONS}

This review was undertaken to gain more knowledge about critical illness neuromuscular weakness in general rather than to investigate specific aspects. It has major limitations in that it encompasses only five original articles and a single review that in summary may not be representative of the entire body of research that is available. Although limited in number, the studies referred to in this review were conducted rigorously, however they were undertaken mostly in single centre settings, and the generalisability of their results are therefore limited. The small number of articles examined also makes it difficult to analyse the quality of life of CIPNM survivors and associated outcomes with any degree of certainty. 


\section{REFERENCES}

Aichenbaum, SR, \& Ring, H. (2003). Rehabilitation of a patient with critical illness polyneuropathy (CIP) following acute respiratory failure: a case report and review of literature. Disability and Rehabilitation 25 (6), 273-276.

Bercker S, Weber-Carstens S, Deja M, Grimm C, Wolf S, Behse F, Busch T, Falke KJ, Kaisers U. (2005). Critical illness polyneuropathy and myopathy in patients with acute respiratory distress syndrome. Critical Care Medicine 33 (4), 711-715.

Coakley JH, Nagendran K, Yarwood GD, Honavar M, Hinds CJ. (1998). Patterns of neurophysological abnormality in prolonged critical illness. Intensive Care Medicine 24 (8), 801-807.

de Letter M-A CJ, Schmitz PI M, Visser LH, Verheul FAM, Schellens RLLA, Op de Coul DAW, van der Meche FG. (2001). Risk factors for the development of polyneuropathy and myopathy in critically ill patients. Critical Care Medicine 29 (12), 2281-2286.

Fletcher SN, Kennedy DD, Ghosh IR, Misra VP, Kiff K, Coakley JH, Hinds CJ. (2003). Persistent neuromuscular and neurophysiologic abnormalities in long-term survivors of prolonged critical illness. Critical Care Medicine 31 (4), 1012-1016.

Garnacho-Montero J, Madrazo-Osuna J, Garcia-Garmendia JL, Ortiz-Leyba C, Jimenez-Jimenez FJ, Barrero-Almodovar A,
Garnacho-Montero MC, Moyano-Del-Estad MR. (2001). Critical illness polyneuropathy: risk factors and clinical consequences. A cohort study in septic patients. Intensive Care Medicine 27 (8), 1288-1296.

Garnacho-Montero J, Amaya-Villar R, Garcia-Garmendia JL, Madrazo-Osuna J, Ortiz-Leyba C. (2005). Effect of critical illness polyneuropathy on the withdrawal from mechanical ventilation and the length of stay in septic patients. Critical Care Medicine 33 (2), 349-354.

Khilnani GC, Bansal R. (2004). Neuromuscular weakness in critically ill. The Journal of the Association of Physicians of India 52 (2), 131-136.

Latronico N, Shehu I, Seghelini E. (2005). Neuromuscular sequelae of critical illness. Current Opinion in Critical Care 11 (4), 381-390.

Thiele RI, Jakob H, Hund E, Tantzky S, Keller S, Kamler M, Herold U, Hagl S. (2000). Sepsis and catecholamine support are the major risk factors for critical illness polyneuropathy after open heart surgery. The Thoracic and Cardiovascular Surgeon 48 (3), 145-150.

Van den Berghe G, Schoonheydt K, Becx P, Bruyninckx F, Wouters PJ. (2005). Insulin therapy protects the central and peripheral nervous system of intensive care patients. Neurology 64 (8), 1348-1353.

Van der Schaaf M, Beelen A, De Vos R. (2004). Functional outcome in patients with critical illness polyneuropathy. Disability and Rehabilitation 26 (20), 1189-1197. 